Advances in Science, Technology and Engineering Systems Journal Vol. 6, No. 2, 499-511 (2021)

www.astesj.com

Special Issue on Multidisciplinary Sciences and Engineering

\title{
Open Access Research Trends in Higher Education: A Literature Review
}

\author{
Mariutsi Alexandra Osorio-Sanabria ${ }^{1, *}$, Astrid Jaime ${ }^{2}$, Tamara Alcantara-Concepcion3, Piedad Barreto ${ }^{4}$ \\ ${ }^{1}$ Universidad Pontificia Bolivariana, Information and Communication Technologies Faculty, Medellín, 050031, Colombia \\ ${ }^{2}$ Universidad El Bosque, Engineering Faculty, Industrial Engineering School, Bogotá, 110121, Colombia \\ ${ }^{3}$ Universidad Nacional Autónoma de Mexico, Department, Institute, Ciudad de México, 04510, Mexico \\ ${ }^{4}$ Universidad Cooperativa de Colombia, Law Faculty, Bogotá, 111311, Colombia
}

\begin{tabular}{l} 
A R T I C L E I N F O \\
\hline Article history: \\
Received: 16 December, 2020 \\
Accepted: 14 February, 2021 \\
Online: 17 March, 2021 \\
\hline Keywords: \\
Open access \\
Higher education \\
Trends \\
\end{tabular}

A B S T R A C T
This study is a review of the literature on open access (OA), seeking to identify trends in
research on the subject. This review was conducted in the SCOPUS database and focused
on the following as the main topics: 1. Financial aspects, 2. Repositories, 3. Education, 4.
Academic community's perception of OA resources, 5. Tools, 6. Policies, 7. Institutions, 8.
Stakeholders, and 9. Impact. Out of these topics, the financial aspect, especially in OA's
publication costs, was identified as driving great interest among researchers in the field. On
the other hand, the study of the impact of OA is a subject little examined. Although research
on OA in the higher education sector analyzes different perspectives and describes advances,
challenges, and concerns, it is fair to conclude that OA encourages the creation and
dissemination of knowledge and academic communication.

\section{Introduction}

At present, scientific knowledge is considered a public good. Information and Communication Technologies (ICT) have not only facilitated its access, transfer, exchange, and reuse [1], but they have also generated new scenarios of control for the academic community over its production [2] in contrast to the monopoly of commercial publishers. From this point of view, open access (OA) is a mechanism and, at the same time, an international movement, whose purpose is that "any person, with an Internet connection, can freely access without economic, technical or legal restrictions to scientific, academic and cultural information" [3].

The development of this movement is supported by various declarations and initiatives such as the Budapest Open Access Initiative [4], the Bethesda Declaration on Open Access Publications [5], the Berlin Declaration on Open Access to Knowledge in Sciences and Humanities [6], the Declaration of Santo Domingo [7] and the Declaration of Salvador [8]. Thus, the implementation of OA represents both an opportunity and a great challenge for society, particularly for Higher Education Institutions (HEIs), where it has aroused strong research interest.

It is not surprising then, that some academics have worked on the research trends observed in this field. In [9], the author present "focuses on the open-access-related conversations embedded within a serials context or OA discussions in publications targeting serials or electronic resource librarians" for the years 2008 to 2009. Likewise, in [10] the author has also tried to identify OA trends. Despite not specifically established, by exploring the bibliography of his work, it can be determined that he bases his work on documents from 1940 to 2013, although the older documents pertain to intellectual property and scientific activity. [11] "presents a conceptual literature review of the subject of open access as it is reflected in the literature relevant to digital library research", through the study of works" (published between 2010 and 2015). As it can be observed, some of these works focus on specific issues and are based on literature published before 2016. For this reason, we are interested in more recent research trends in OA in HEIs, given the central role it plays in OA, to achieve an

${ }^{*}$ Corresponding Author: Mariutsi Alexandra Osorio-Sanabria, Engineering PhD student, mariutsi.osorio@upb.edu.co 
overview of the current concerns of the academic community in this field.

In the next section, the studies related to the object of study are presented followed by the methodology that guided the work carried out. Subsequently, the results and the discussion derived from the identification of the topics addressed in the OA studies are introduced prior to the conclusions.

\section{Related work}

OA refers to the dissemination of scientific research results, in digital format, which has undergone a peer-review process and doesn't charge subscription fees [12]. There are multiple definitions of this notion. For example, [13] bases its work on the Budapest OA Initiative, the Bethesda Declaration on Open Access Publishing, and the Berlin Declaration on OA to Knowledge in Science and Humanities, to propose "the BBB definition of OA" and summarizes the three definitions of OA as follows: "OA literature is digital, online, free of charge, and free from most copyright and licensing restrictions." For his part, in [14] is defines OA as "access online, at no cost, to peer-reviewed scientific content with limited copyright and licensing restrictions." On the other hand, Uribe-Tirado indicates that the $\mathrm{OA}$ is the right anyone has, without registration, subscription, or payment restrictions, to be able to read, download, copy, distribute, print, search or link the full texts or educational, scientific, or other digital content, and use them in a legitimate way according to the Creative Commons licenses assumed [12].

Furthermore, from the different definitions of OA, several issues around the OA movement have been studied. A few of these works focused on the research trends that can be observed in this field, as mentioned in section 1. In [9] the author identifies, for the years 2008 to 2009, five issues: (i) the NIH Mandates, (ii) "the increasing number of access policies adopted by universities", (iii) the "Arguments promoting OA" (par. 42), (iv) the strategies deployed to increase acceptance of OA among faculty, and (v) the roles different actors should adopt in supporting the OA movement (par. 43). The study [10] proposed four trends: "New OA publication channels" (p. 82), "legal aspects of academic publishing and OA Publishing" (p. 114), new business models around OA, and "Mandates, both institutional and from funding organizations" (p. 186). Finally, in [11] the author focusing on OA "literature relevant to digital library research" (p. 2), identifies five categories: "Open Access, Authors, Scholarly Communication, Libraries and Librarians, and Developing and Transitional Countries." (p. 2). Table 1 summarizes the trends recognized by these works, identifying the authors that distinguish each one.

Table 1: Research trends identified.

\begin{tabular}{|l|l|}
\hline Research trends & Source \\
\hline Policies and Mandates & {$[9,10]$} \\
\hline Arguments promoting OA & {$[9]$} \\
\hline Acceptance of OA & {$[9]$} \\
\hline Actors and their roles (Authors, Librarians) & {$[9,11]$} \\
\hline OA publication channels & {$[10]$} \\
\hline Legal aspects of OAP & {$[10]$} \\
\hline Business models around OA & {$[10]$} \\
\hline Manifestations, Barriers, and Benefits of OA & {$[11]$} \\
\hline
\end{tabular}

\begin{tabular}{|l|l|}
\hline Scholarly Communication & {$[11]$} \\
\hline Libraries & {$[11]$} \\
\hline Developing and Transitional Countries & {$[11]$} \\
\hline
\end{tabular}

As it can be established, there are just a few trends identified by more than one author, which is not surprising given the specificity of the focus of each work. For that reason, we are interested in analyzing current trends in research in the OA field. Although we had recently studied this subject [1], the dynamics of the field has led us to further explore if new trends in OA research in HEIs have emerged.

\section{Methodology}

There is an increase in research to conceptualize relevant issues and aspects of open access. For this reason, it is essential to summarize and provide an overview of these proposals. The existing literature is examined with a Systematic Mapping of Literature $[15,16]$. This method makes it possible to systematically and objectively identify the scope of available empirical studies to answer specific research questions. The review process has four stages: (1) Definition of research questions, (2) Search strategy, (3) Inclusion and exclusion criteria; and (4) Classification of documents (figure 1). The study stages are described below in the following subsections.

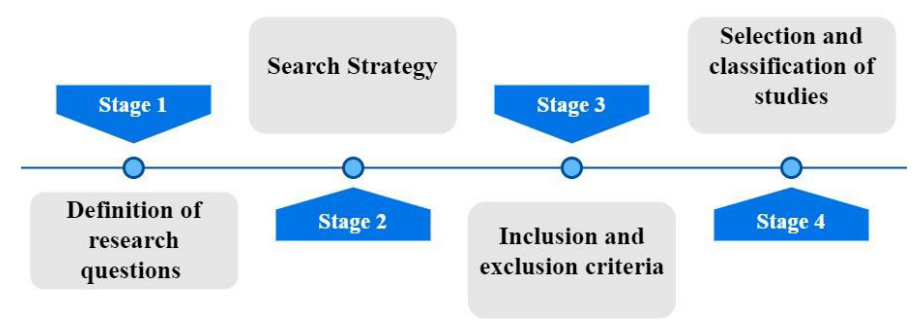

Figure 1: Methodology

\subsection{Definition research questions}

This study aims to identify the advances, topics, and trends of $\mathrm{OA}$ research and which aspects are being analyzed. Three research questions associated with the objective of the study are defined and addressed:

- What is the distribution of the publications of OA studies regarding HEIs?

- What are the topics of OA studies identified in the literature?

- What are the trends in OA considered by the studies identified in the literature?

\subsection{Search Strategy}

The review intends to find primary studies about OA research using a search strategy in the SCOPUS database. The search was developed through the review of the data needed to answer the research questions.

The terms "open access" and "higher education institution" were defined as keywords. These terms are connected with the conjunction "AND", yielding the search string:

("open access") and ("higher education institution") 
The search was limited to the title of the study, and journal articles, excluding articles published in conferences, books, and others. The result of applying the search equation to the selected database was 871 documents. Subsequently, 11 duplicates were identified and removed.

\subsection{Inclusion and exclusion criteria}

We defined inclusion and exclusion criteria filters and selected relevant studies to answer the research questions.

The inclusion criteria for papers are:

- $\quad$ Research published between 2010 and 2020.

- Research that explicitly mentions the term open access and higher education institution in the title and abstract and present a contribution to the $\mathrm{OA}$ issue.

- Research in areas other than the health sciences.

The exclusion criteria of the papers applied are:

- Research focuses which is unrelated to OA.

- Duplicate studies, only the most recent is included.

- Research that is not published as peer-reviewed journal articles.

\subsection{Selection and classification of studies}

We identified the main articles that provided direct evidence on the research questions. The search is limited to studies published between 2010 and 2020. The initial step was to search SCOPUS, using the search equation (1).

The selection of primary studies implies three eligibility filters to select the relevant results: year of publication, full-text availability, and research of areas other than the health sciences.

Figure 2 summarizes the systematic literature review process in a diagrammatic format according to the PRISMA Statement [17], indicating the number of studies in each phase. The studies were analyzed and selected by four reviewers. Each reviewer opined on whether to approve or reject each study.
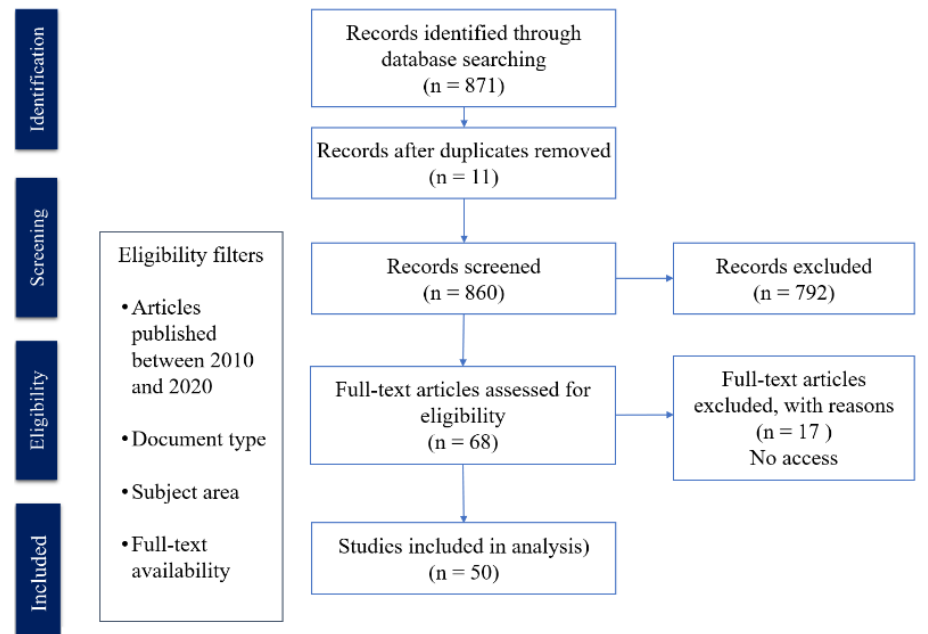

Figure 2: Number of included articles during the study selection process
As a result of the systematic literature review process, 50 primary studies were selected. These studies were organized in different categories as presented in Table 2.

Table 2: Classification according to trend

\begin{tabular}{|c|c|}
\hline Trend & Description \\
\hline $\begin{array}{l}\text { Financial } \\
\text { aspects }\end{array}$ & $\begin{array}{l}\text { Aspects related to the costs and monetary } \\
\text { difficulties linked to OA. }\end{array}$ \\
\hline Repositories & $\begin{array}{l}\text { Set of systems and services that facilitate the } \\
\text { storage, management, retrieval, presentation, } \\
\text { and reuse of digital content [18]. }\end{array}$ \\
\hline Education & $\begin{array}{l}\text { Aspects related to the impact of OA on the } \\
\text { teaching process of the higher education } \\
\text { sector. }\end{array}$ \\
\hline $\begin{array}{l}\text { Perceptions } \\
\text { about the use } \\
\text { of } \text { OA } \\
\text { resources }\end{array}$ & $\begin{array}{l}\text { Surveys and interviews to consult the } \\
\text { academic communities' opinion (students, } \\
\text { professors, and/or researchers), about their } \\
\text { experiences when using OA resources. }\end{array}$ \\
\hline Tools & $\begin{array}{l}\text { Use of ICTs that allows the transformation } \\
\text { from closed access to OA in scientific } \\
\text { publications [19]. }\end{array}$ \\
\hline $\begin{array}{l}\text { Policies on } \\
\text { OA }\end{array}$ & $\begin{array}{l}\text { Regulations and guidelines about initiatives } \\
\text { of OA and licenses of use. }\end{array}$ \\
\hline Institutions & $\begin{array}{l}\text { Aspects related to the changing roles, } \\
\text { policies, and practices of the institutions } \\
\text { participating in the OA Ecosystem. }\end{array}$ \\
\hline Stakeholders & $\begin{array}{l}\text { Actors that participate and influence the OA } \\
\text { ecosystem. }\end{array}$ \\
\hline Impact & $\begin{array}{l}\text { Changes produced on the environment, } \\
\text { processes, products or in some population } \\
\text { groups, due to a certain action [20]. }\end{array}$ \\
\hline
\end{tabular}

\section{Findings}

The research questions stated above (see section 3.1). are responded through the analysis performed. For this reason, this section is organized according to each one of these questions. The first issue addressed is the distribution of the publications, then the topics, and, finally, the trends in OA considered by the studies identified in the literature.

\subsection{Distribution of publications on OA regarding HEIs}

We analyzed 50 studies on OA in HEIs, published between the years 2010 and 2020 . We observed that 2019 was the year with the highest number of publications, with 15 works. These results show a growing interest in the subject of $\mathrm{OA}$ for the higher education sector. Figure 3 below shows the distribution of documents by year.

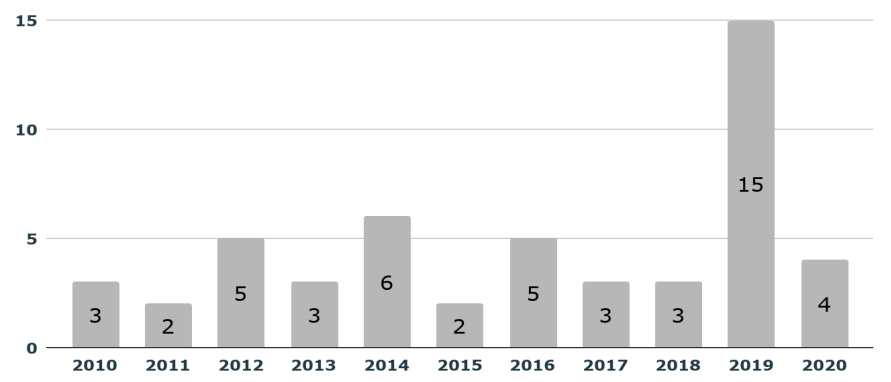

Year

Figure 3: Documents analyzed by year 
It is also important to note that the result for the year 2020 does not include the whole year, because the search was done on September 15 th, 2020.

On the other hand, we analyzed the distribution of the selected works according to the country in which the study was carried out. We noted that $24 \%$ of the studies were conducted in the UK, $10 \%$ in Austria, 8\% in South Africa and India, and 6\% in Brazil and Australia. On the other hand, $38 \%$ of the remaining works were conducted in Canada, Egypt, Ecuador, France, Germany, Kenya, Mexico, Nigeria, the United Arab Emirates, Slovenia, United States, Zimbabwe, and countries not defined (Table 3). Furthermore, only one study focuses on Latin America and another one in Europe. In the Latin American context, we observed that OA in HEIs has been analyzed in Argentina, Brasil, Costa Rica, Peru, and Mexico. Figure 4 below shows the documents analyzed by the country mentioned in the research.

Table 3: Classification according to country

\begin{tabular}{|l|c|l|}
\hline Country & Documents & Sources \\
\hline United Kingdom & 12 & {$[21-32]$} \\
\hline Austria & 5 & {$[19,33-36]$} \\
\hline India & 4 & {$[37-40]$} \\
\hline South Africa & 4 & {$[41-44]$} \\
\hline Australia & 3 & {$[45-47]$} \\
\hline Brazil & 3 & {$[48-50]$} \\
\hline Mexico & 2 & {$[51,52]$} \\
\hline United States & 2 & {$[53,54]$} \\
\hline Canada & 1 & {$[55]$} \\
\hline Ecuador & 1 & {$[56]$} \\
\hline Egypt & 1 & {$[57]$} \\
\hline Slovenia & 1 & {$[58]$} \\
\hline France & 1 & {$[59]$} \\
\hline Germany & 1 & {$[60]$} \\
\hline Kenya & 1 & {$[61]$} \\
\hline Nigeria & 1 & {$[62]$} \\
\hline United Arab Emirates & 1 & {$[63]$} \\
\hline Zimbabwe & 1 & {$[64]$} \\
\hline Latin America & 1 & {$[65]$} \\
\hline Europa & 1 & {$[66]$} \\
\hline Country is not defined & 3 & {$[2,67,68]$} \\
\hline Total & 50 & \\
\hline
\end{tabular}

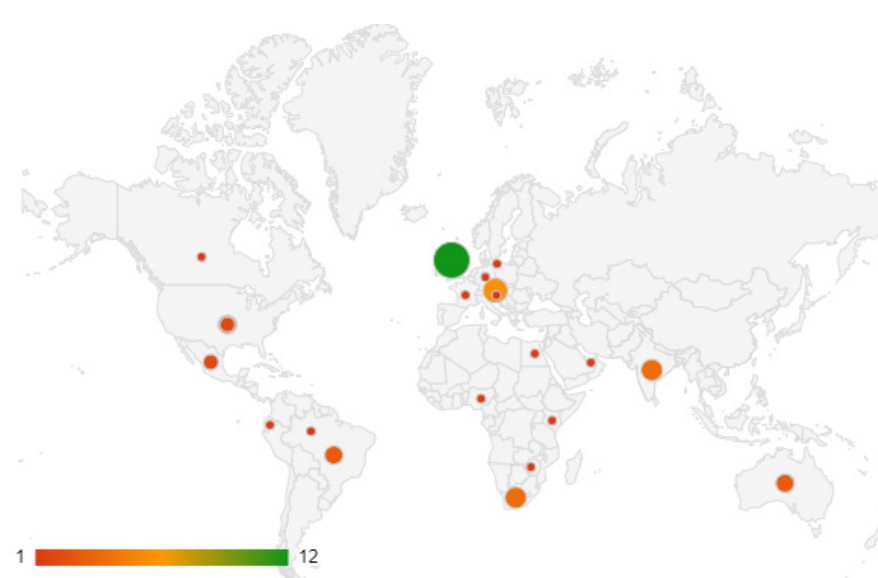

Figure 4: Documents analyzed by country

\subsection{Topics emerging from the studies}

To identify and classify the selected studies according to the authors' contribution. The trends defined in Table 5 were the ones that emerged from the analysis of the selected works. Table 4 presents the results of the classification. The trend with the most associated studies is focusing on the financial aspects (32\%), followed by research related to repositories $(22 \%)$, and education $(12 \%)$.

Table 4: Classification according to trend

\begin{tabular}{|l|c|l|}
\hline Country & Documents & Sources \\
\hline $\begin{array}{l}\text { Financial } \\
\text { Aspects }\end{array}$ & 16 & $\begin{array}{l}{[2,19,21,22,28,30,33-} \\
36,38-43,54,67]\end{array}$ \\
\hline Repositories & 12 & $\begin{array}{l}{[29,37,41,44,45,51,52,} \\
56,58,61,62,64]\end{array}$ \\
\hline Education & 6 & {$[47,49,55,65,68,69]$} \\
\hline Perceptions & 5 & {$[32,39,48,57,59]$} \\
\hline Tools & 5 & {$[38,40,50,58,66]$} \\
\hline Policies & 4 & {$[25,31,45,53]$} \\
\hline Institutions & 2 & {$[27,63]$} \\
\hline Stakeholders & 2 & {$[23,46]$} \\
\hline Impact & 2 & {$[42,60]$} \\
\hline Total & $54^{\text {a }}$ & \\
Note: The results show a higher number of documents because four \\
documents support more than one trend.
\end{tabular}

\subsection{Trends}

Below, we present the main trends that emerged from the review process as well as some aspects that stand out in each one.

\subsubsection{Financial Aspects}

Several authors have focused on different aspects related to the financial difficulties linked to OA. They treat aspects such as the costs of OA for universities [22,28,30,42,54,67], strategies used by some publishers for addressing OA [2], financial challenges for implementing policies for incentivizing OA [19,21,22,33-36,54], and transformative agreements [43].

In [28], the authors investigated the administrative costs incurred by 29 UK universities to publish research results in OA in the "Gold" or "Green" route. The analysis considers the author's time, peer review time, administrative staff time, and academic management time. It identifies that the time and cost invested by universities in the Gold Route is 2.5 times greater than in the Green route, which is faster and less costly. While universities recognize the importance of increasing access to their research results through OA, they are also concerned about the costs involved. On the other hand, [30] determined that the costs of Article Processing Charges (APC) and subscription to journals have increased in HEIs from the UK identifying that the increase in the adoption of OA has created pressures in terms of costs for these institutions. Furthermore, they observed that there is a correlation between the price of APC and the quality of the journals.

For his part, in [67] the author analyzes the impact of indexed Gold OA journals to increase available content, citation frequency, and access to content published by recognized publishers, universities, society, or specific groups. It identifies 
the growth of Gold OA journals and their inclusion in indexing and abstract databases. However, this research also highlights the fact that costs of access to academic databases offered to universities have not decreased.

In [54]. the author examined the OA Textbooks and Open Educational Resources processes to promote, evaluate, preserve, curate, and facilitate its access as well as the funding required to incorporate them into repositories in the United States. He found that the main role that libraries have is to make this kind of education resources affordable and accessible [54]. Moreover, a study carried out on South African universities, mentioned some challenges associated with the dissemination of knowledge resulting from African research due to the new APC financing model, which implies that institutions must assume this additional cost to traditional research funding, research staff salaries, and journal access licenses available to the educational community. It also highlights risks of low visibility in the absence of resources to assume the costs of the new financing model [42].

On the other hand, in [2] the authors highlight how commercial publishers appropriated academic communication spaces, turning them into an inelastic market that hinders the circulation of knowledge. It finds two sources of financing: either the authors pay APCs; or they find external sponsorships and grants through advertising, donations, and fundraising. These two routes relate to the gold and green access models, respectively.

In [21], the author reported the important steps to the growth of OA in the UK, in 2012. Initially, the Fintech recommendations to the Minister of Universities and Science, followed by the new UK Research Councils policy adopting the Finch Group recommendations. The Fintech report recommended increasing access through three mechanisms - OA journals, extensions to licensing, and repositories. That being said, the Fintech report had some adverse reactions mainly because of the lack of price regulation, and because they estimated some transitions that institutions cannot afford because of the limits of their budgets [21].

Following a survey from 2019 to adopt central funds for the payment of $\mathrm{OA}$ in high education institutions, the authors repeated the survey in 2011 finding there were not big advances to encourage the OA publications in 26 UK universities [22]. The possible reasons stated were high APC publication charges, difficulty to associate publishing costs with a related grant, the administrative overhead associated with managing micropayments for APCs, difficulties associated with raising awareness of the fund amongst authors, and perception challenges amongst researchers linking OA with lower quality of the results presented in the investigations which affect current levels of demand [22].

A group of authors focused their attention on the "Austrian Transition to Open Access (AT2OA)", authorized by the Austrian Federal Ministry of Science, Research and Economy [19,33,35,38-41]. According to [29] in this project, running from 2017 to 2020 , "the 21 public universities cooperate to promote OA through concerted measures" [29]. This initiative included four subprojects that focused on: "drafting an expert's report about the financial impact of a total adjustment to OA on a national and institutional basis, the extension of existing consortium licenses with an OA component, establishment of an OA publishing fund as well as the promotion of OA monographs and suitable OA infrastructures" [33]. In contrast, in [34] the authors deal with "a number of questions that were discussed in the course of the drafting of a guidance document around funding conditions for publication funds in the project" (p. 1). While in [36] the authors describe "the prerequisites for an equitable and appropriate use of central funds for such transitional business models, and present a case study of a currently running, successful agreement". Finally, in [35] the author summarizes the methods and findings of the final report of the AT2OA-Transition-Study.

Finally, in [43] the author focuses on transformative agreements as an advance towards "a new global publishing regime where scholarly communication is available and free for all readers with internet access". According to the author, this change has been primarily caused by "bottom-up pressures from university systems and researchers as producers of knowledge, but it also represents a reflection of many new adventures towards the imagination of the intricate and complex relationships between science and society" [43]. Special attention is paid to the OA2020 project, which "calls on the publishing houses to flip their journals from being 'pay to read' to 'pay to publish' [43]. Examples of institutions and countries committed to the OA2020 route are the University of California system and China, as well as Sweden, Germany, the Netherlands, and Norway which are putting pressure on Elsevier to "come to the negotiating table to strike up a 'pay-to-publish' model rather than the 'pay-to-read' one" [43]. Another example of an alternative negotiation model is the SCOAP3 [South African OA publishing] project, coordinated by the European Organization for Nuclear Research (CERN). The project includes a centralized fund. "The project negotiated with the publishers of all the key particle physics journals to enter the kind of agreement captured by OA2020. Each country contributes to the central fund an amount, which is directly proportional to its international share of the publications output, which for South Africa is $0.5 \%$ of the global output, and therefore a national contribution of $0.5 \%$ of the total central fund. This makes particle physics articles, even in the most high-impact, prestigious journals, openly accessible to all. CERN manages the payment for the publication of the articles. It is an example of diamond OA where there is no APCs or "author facing charges" [43].

\subsubsection{Repositories}

Works on repositories focus on diagnosing existing repositories $[56,70]$, presenting specific projects or initiatives for putting in place repositories $[29,37,41,51,52,56,61]$, or in studying the challenges faced by researchers and other stakeholders for embracing OA. These challenges could be partly mitigated, if they took advantage of repositories $[44,62,64]$, while others show the challenges for fully taking advantage of repositories [45,58].

In [51], the authors studied the growth of repositories around the world from 2006 to 2012. However, repositories were not well known in that time. That being said, there were universities' efforts to constitute meta-search engines, catalogs, and directories to make available valid and reliable information. In the LatinAmerican case, the author presents advances of open repositories in Costa Rica, Peru, Argentina, and Mexico. It also includes the 
infrastructure development, its geographic distribution, and some policy initiatives. Then again, in [56] the authors executed a diagnosis and classification of 30 institutional repositories in Ecuador. As a result of the study, they identified that most of the repositories correspond to databases managed by private HEIs, with DSPACE being the most widely used software. However, only $11.37 \%$ of IRs use a Creative Commons license, and 7.23\% do not indicate the type of license they use.

In the same way, in [52] the authors shown an overview of OA repositories of HEIs in Mexico. They analyzed eleven repositories, which have the highest levels of resources in OpenDOAR. The authors conclude that these repositories are an important alternative for the visibility of resources and keep a growing tendency in the quantity and quality of the resources included in OA repositories. Nevertheless, these authors also noted that there are important challenges shared by the repositories analyzed. It is worth mentioning that according to the authors, there is a Mexican Network of Institutional Repositories (REMERI by its initials in Spanish), which has defined General Guidelines for OA. REMERI declares the repository program, aiming at collecting, preserving, and ensuring OA to Scientific, Technological and Innovation Information Resources generated mainly with public resources [52].

At the same time, Singh studies the development of OA repositories in higher education and research institutions in India [37]. The study analyzes the growth, development, geographical distribution, and technical characteristics of the repositories such as software, size, and type of content, OA policy, and protocol for metadata collection. It shows that university libraries have implemented OA IRs to improve service to users and to obtain benefits for both the universities and the academic and research communities in terms of visibility and dissemination of research material to the community.

Researchers from Uganda report an OA project called African Higher Education Research Online (AHERO) to establish a better communication of research among HEIs, making more accessible information resources. This repository is semi-automated and focuses on African education. An online survey to evaluate AHERO was made among 26 countries; and the results showed this repository has been successful especially among Uganda, South Africa, and Kenya users, and could represent the start point to encourage OA among disciplinary communities in Africa [41].

Moreover, McCutcheon and Eadie present the development of IR from the University of Glasgow in the UK as a resource for managing OA [29]. The repository considers the UK's OA policy, the University's OA flow, and the provisions defined by funding funds such as the UK Charities Open Access Fund, the European Union, other funder policies, and internal reporting requirements. Additionally, they considered the national standards for OA Metadata proposed by RCUK (Research Councils UK), REF (Research Excellence Framework), the EU, the CASRAI (Consortia Advancing Standards in Research Administration Information) UK Open Access Working Group, as well as internal requirements.
In 2010, in [61] the author presented that reported to the Kenya Information Preservation Society (KIPS) an initiative to make available bibliographic details and abstracts of electronic theses and dissertations, since 1999. KIPS had a collection of approximately 15,000 citations in the database and 24 organizations contributing records on all disciplines. The author concludes that: "it is asserted that digital theses and dissertations massively increase the impact of institutional research, an essential consideration at a time when evidence of the impact of research is becoming an all-important factor in research evaluation, and therefore in future funding [61].

In [44], the authors focused on OA practices (OAPs) and the challenges faced by African researchers. Among these challenges, there are some for accessing materials, such as the unawareness of "Resarch4Life availability, inadequate staffing by LIS"1 professionals and infrastructure challenges". They also faced challenges to publish their research papers in OA. According to the authors, these, among other issues, "are the reasons why most African academic institutions are unable to embrace OAPs" [44]. Furthermore, indicated "OAPs can provide a roadmap in research paper publication in academic institutions, which then can be discoverable, implementable and achievable, also demonstrate the value of academic libraries to their institutions and hopefully provide continual sources of funding." [44].

The approach proposed by the authors in [64] analyzes the roles of stakeholders in strengthening the OA initiatives among academic libraries in Zimbabwe. According to the study, "faculty participants confirmed that academic libraries in Zimbabwe could effectively use IRs to generate new e-content and explore opportunities to license their content". They also found that "Academic institutions are also benefiting from OA initiatives as shown by the growing strength of a research culture in all institutions. It is imperative to take into consideration several challenges ranging from costs, an unwillingness by authors to generate content, unclear systems to coordinate and promote the sharing of knowledge, lack of support from institutional management, and copyright issues" [26].

In the same sense, the library's role in encouraging open repositories was studied in Nigeria and its possible contributions to reach Vision 20: 2020 objectives of economic growth. An important conclusion of the study established the lack of dialogue among stakeholders to encourage the accessibility and utilization of research outputs and intellectual products at Nigerian academy institutions. Conclusion: there is a clear need for a National Policy to set up OA repositories. It is necessary to establish national coordination and implementation mechanisms for the policy, as the international and national cooperation among high educational institutions adopt best practices and models to develop open repositories and to contribute effectively into Nigeria's economic objectives [62].

In [58], the authors point out that despite the great benefits that the development of a single OA portal brings to society, this is not always possible as indicated by the Slovenia's case in which a complete unification was impossible due to the differences in the

${ }^{1}$ LIS: Library and Information Sciences 
control of plagiarism recognition in documents deposited in institutional repositories.

In different circumstances in [45], the authors mentions that one of the greatest challenges for repositories is to insert in the academic culture a favorable environment towards open research data, since collecting, managing, and publishing for future reuse are not phases traditionally carried out. This implies an important change in which, since the commercial publishers are not present because they are not part of their business model, new dialogues between the academic communities are necessary to create stimuli that facilitate their acceptance.

\subsubsection{Education}

In this category, are the studies that focused on the perception $[47,68]$ and use of OA to support the teaching process in higher education $[49,55,69]$, both classroom-based and distancelearning.

In [47], the authors study OA enabling courses in Australian HEI' ${ }^{2}$ institutions "The study examined the following areas: learning barriers faced by students, student engagement and experience in learning, skills developed, and further skills needed while undertaking OA courses, motivation to complete study, career pathway of students, key reasons for selecting particular pathways" [47].

For their part, in [69] the authors analyze the impact of academic literature $\mathrm{OA}$ on the teaching process of the higher education sector in the United Kingdom. Among the perceived benefits is the easy and quick access to content to support teaching without the need to pay additional licensing fees. However, knowledge barriers persist around the location, permanence, legality, and licensing of articles. Thus, they recommend encouraging researchers to license their content to facilitate its reuse [69]. Moreover, [49] conducts a case study at the Federal University of Minas Gerais in Brazil to identify whether the OA to information resources provided by university libraries, contributes to distance learning. Although the libraries indeed offer databases, collections, and digital libraries of Theses and Dissertations, only two resources are from OA, which implies making investments to cover the fees for accessing some databases. In this sense, the potential of OA is evident: institutions can find alternative ways to access content and strengthen the democratization of knowledge and education [49].

Similarly, in [68] the authors conducted a study of the experiences and perceptions of OA held by teachers teaching online in different humanities, social science, and science programs at institutions in the United States, Australia, India, and the United Kingdom. The study showed that participants perceive OA in five different ways, specifically as: 1) a teaching resource, 2) a publishing channel, 3) a social movement, 4) open source; and 5) "free to me" (p. 128). Additionally, each form presented six variations of perception: 1) materials, 2) costs, 3) platforms, 4) benefits, 5) drawbacks, and 6) professional context or purpose. Considering that, there are divergent understandings of OA, publishers, university libraries, and higher education administrators are encouraged to propose strategies to improve dissemination, communication, and further study of aspects of OA [68].

In [55], the authors established the emergence of open education in 2001 with the MIT OpenCourseWare project; and make a historical and philosophical account, highlighting the most important courses around the World. After presenting a statistical analysis of 14 current journals in curriculum studies, the study concludes that they reflect globalization and economic systems in the educational offer; however, authors question the possibility to create spaces with a different perspective, encouraging knowledge as a social good [55].

In Latin America, Tzoc concludes that universities in the region should work in three scenarios to promote OA: 1) increase of institutional agreements and research projects between universities; 2) increased participation of Latin American teachers in professional networks or foreign projects, and 3) proliferation of open, distance, or virtual education programs [65].

\subsubsection{Perceptions}

There is an important group of studies that analyze the perception and adoption of OA by the academic community. This group focuses on attitudes towards OA [32,39,48,59], as well as on the use of resources and services available $[48,57]$.

In [39], the authors study how well the teaching community working in HEIs in Tamil Nadu (India) endorse the OA publishing model. The study shows that most of the teaching staff prefer the OA publishing model to the other commercial and hybrid publication models [39].

In contrast, in [32] the author examined the perceptions, development, and conceptions of OA practices in HEIs in the United Kingdom, through an ethnographic study. The results of the study focused on the barriers perceived by the academic community affecting the adoption of OA. The main perceived barriers are operational, technological, political, or legal, and community knowledge and attitudes towards OA. Addressing these barriers will involve developing different strategies that generate cultural acceptance of possible forms of open knowledge dissemination [32].

In [59] the author analyzes the results of the survey conducted by French consortium Couperin (Unified Consortium of Higher Education and Research Organizations for Access to Numerical Publications). The survey aims to understand researchers' practices and opinions regarding $\mathrm{OA}$ and the use of social networks. The results show the importance of promoting information related to editorial policies and intellectual property rights. Also, it identifies the opportunity to link the OA and social networks, to promote open science, and increase the visibility of researchers.

For his part, in [57] the author studied the student's adoption of OA online higher education services in Egypt. The study has divided into two phases: 11 deep interviews of information directors of some universities, and senior managers of the

\footnotetext{
${ }^{2}$ The search by author, title or year in My Library (2019) OA enabling courses are preparatory [44] 
Ministry of Higher Education, and the second phase consisted of student surveys from three universities (public, private, and foreign) [57]. The interviews were structured to test and support the model and the elements that determine the adoption of OA online education. These elements are: a) internal attributes, composed by Facilities and resources, faculty and staff support and quality and risk control b) External, integrated by Socioeconomic factors, Market structure, and competition and government support; c) The perception of open innovation attributes has five elements: relative advantage; compatibility; observability; trialability and complexity; d) Faculty innovation adoption and e) Students innovation adoption [57].

Moreover, in [48] the authors presented the results of an OA perception survey of the scientific literature, as well as the use and citation of OA sources. Brazilian researchers responded to the survey. They found that although the researchers know and support the principles of OA, there is low awareness and use of OA repositories. One of the causes identified was the confusion regarding the article's copyright $\mathrm{s}$ that could be published in a repository since researchers believe that the papers that should be available are post-prints. Thus, they recommend increasing the awareness of the research community on these issues.

\subsubsection{Tools}

In this trend, the works related to tools aimed at facilitating the development, use, or access to digital resources are included. A group of works focuses on tools that integrate different resources $[38,40,50]$, while others propose tools to complement the integration efforts [58] and others work on the elements necessary for developing and publishing open academic courses, including the tools that would allow different national standards to be compatible [66].

Swain focuses on Virtual Libraries in Higher Education in modern India and their role in the "formation and dissemination of information and knowledge" [36]. This work focuses on INFLIBNET, which "may be given the status of master repository having linkage with all institutional repositories" [36]. INFLIBNET is the Information and Library Network Centre initiated by the University Grants Commission in $1991^{3}$.

In [50], the authors describe the development of a tool that facilitates data integration between the Institutional Repository (IR) of the Federal University of the Amazon, the scientific initiation management system (Lira portal), and the faculty portal. This work contributed to the automation of the flow of deposit and dissemination of scientific initiation projects in the University's IR as a strategy to promote the OA.

In [38], the authors describe the development of a Research Archive Information Retrieval and Visualization System for Indian universities. This system allows access and consultation in the OA of digital resources in the Bengali language. From the prototype created, the aim is, among other results, to promote OA through the dissemination and international visibility of research results.

In [58], the authors point out that before the integration of institutional repositories in a single search engine, it is important to develop expert plagiarism detection systems based on the design of algorithms that make comparisons between documents. This system was developed in Slovenia, including an exhaustive analysis of documents. This analysis considers linguistic qualities, identification of similarities higher than $60 \%$, and results show. These results show the first five documents that stand out for exceeding the originality threshold. Furthermore, making visible criteria such as visits, downloads, previous readers' ratings, among others.

In [66] the authors reviewed, in Greece, the ASK-CDMECTS. This tool facilitates the authoring and publishing of open academic courses using the CDM-ECTS metadata description. Their analysis involves a review of Norway, USA, India, UK, China, and Japan initiatives and the required structure composed of 18 elements to constitute an open course. Another interesting element is the consideration of standards to describe an open course. In this case, a subset in XML format, compatible between two standards was proposed: the CDM standard developed by the University of Oslo for the Norwegian for higher education, and the ECTS standard adopted by high educational institutions in Europe [66].

\subsubsection{Policies}

The development of the OA has given way to the definition of policies in HEIs. The analyses performed and trends in policy development for OA promotion [45], knowledge communication [31], open courses [25], and commercial exploitation of research results [53].

In [45], the authors show that the OA generated a globalization scenario around education policy thanks to two strategic allies, such as governments and libraries. The first, defined policies with an emphasis on the promotion of OA, compliance frameworks, and infrastructure proposals like the creation of portals of $\mathrm{OA}$; and the second, libraries, with the creation of institutional repositories, and the design of strategies to strengthen the culture of selfarchiving in the academic community.

In [31], the authors analyze the use and implementation of the UK Scholarly Communication Licensing policy (UK-SCL) as a strategy that encourages OA and allows control of the content produced in HEIs. The results identify perceived benefits in helping authors gain control of their publications, disseminate publications rapidly and widely, and reduce costs at institutions. On the other hand, the perceived challenges identified are resistance from editors, administrative demands, and confusion among researchers [31]. Also, the factors influencing policy adoption are institutional collaborations, external support, internal communication and engagement, the legal framework, business processes, and the role of the library within the institution [31].

In [53], the author studied the OA advances and situation and proposed an agenda to encourage the legislation to avoid the commercial exploitation of research results and to allow the growth of OA. The proposed agenda encourages higher education researchers and leaders to advance OA by lobbying Congress to pass the FRPAA legislation. The proposed agenda encourages higher education researchers and leaders to advance OA by

\footnotetext{
${ }^{3}$ https://inflibnet.ac.in/about/index.php Accessed on September 17th, 2020. 
lobbying Congress to pass the FRPAA legislation. Furthermore, it works with funding agencies to obtain policies to support OA publication rates; establish institutional funds to support LO publication charges not covered by grants; approve OA mandates on campus and support local IRs in depositing research, and publishers in the formalization of agreements that allow wide and unrestricted distribution of research.

Finally, OA scholarly publishing as mega-journals and academic networking services as in the case of Massive Online Open Courses (MOOCs) currently represent an innovative and disruptive educational form. A study in the UK and USA shows the emergence of policy initiatives to regulate these new forms of academic scope. It is important to notice the economic impact encouraged by this kind of information and educational industry, transforming the traditional academic markets [25].

\subsubsection{Institutions}

Some authors have focused their attention on the changing roles [27], policies, and practices of the institutions participating in the OA Ecosystem [63].

A case study carried out in the United Kingdom reference how, since 2005, this country has an OA policy [27]. Also, the financing of APC has evolved, since, at first, it was the UK Research Council that was directly in charge of providing the resources individually requested. However, since 2013, these costs are managed and allocated by the research organizations to which the researchers are ascribed. The resources are assigned in a single item, to these organizations. In turn, they oversee transparently managing and allocating them, according to criteria of coverage of disciplines and researchers, at different stages of their career, in compliance with the OA policy.

In [63] the authors study the role of HEIs in the United Arab Emirates (UAE) OA uptake. Their results suggest that although "there seems to be a generally positive perception of OA", there is also a moderate adoption of OA policies and practices. They also point out the need to create a culture that increases priority for OA adoption, as well as "awareness, policies, best practices, and infrastructure" [63]. They also suggest the need for "nationwide strategies aligned with international initiatives such as OA2020 and Plan S need to be adopted" if the UAE is to increase its presence in the OA movement [63].

\subsubsection{Stakeholders}

This trend presents analysis on different stakeholder groups, such as New University Presses [23] and Australian universities [46], presenting the challenges and opportunities these stakeholder groups face.

In [23], the authors studied the University of Huddersfield Press (the Press), one of the 21 New University Presses (NUPs) in the UK, the vast majority of which publish OA journals and monographs. Taylor establishes six key areas on which "the Press has focused on since 2016 to enable a professional, efficient and effective publishing process that suits our journal and monograph portfolio: Commissioning; Review; Production; Discoverability; Marketing; and Analytics. Furthermore, the author emphasizes the importance for OA publications to be transparent, given the rise of predatory OA journals, and to be recognized as academic publications of high standards and professional quality. According to [23], the Press aims at optimizing the publishing process to achieve a "streamlined workflow, increased discoverability, an improved level of service for authors and editors, an improved reader experience, and ultimately, a steady and measurable increase in downloads and citations" [59, p. 10]. Finally, The Press has proposed a Press Model for university presses.

In [46] the author carried out in a study carried out in Australian universities, points out how the OA scenario is being unduly exploited by agents who develop practices that could be classified as unfair, which generates new actions on the part of the universities who must accompany researchers by providing advice and new tools to identify those journals that meet the desired quality and reputation standards to send their research results.

\subsubsection{Impact}

In this trend, we find the works that study how OA has altered research [42] and knowledge management activities [60].

In [42], the authors highlight that the dynamics of the research culture have changed from a linear structure- in which the purpose of an investigation is the publication of its results-, to give way to the creation of virtuous circles, around sharing and reusing research data which can be advantageous for developing countries.

A study published in 2010, analyzed the impact of OA on the Socialization, Externalization, Combination, and Internalization (SECI) model from Nonaka applied for higher education institutions. The study concludes that $\mathrm{OA}$ is a positive factor for knowledge Management because it makes scientific literature openly accessible for anyone interested in the creation, retrieval, and transfer of scientific knowledge. The OA contributions are resumed as the acceleration of the spiral of knowledge creation; Improvement of transfer into wide dissemination mechanisms; OA also changes the method of storing and retrieving scientific online information; now in repositories; and finally, a potential decrease in the costs of scholarly communication [60].

\section{Discussion}

This study looks at the current interests of researchers in the OA field in the HEIs sector. As mentioned before, although we had recently studied this subject [1], updating it, showed new trends in OA research in education. We had previously found that researchers were focusing their work mainly on the repositories, journals, tools, and perceptions of the use of OA resources. However, our new study allowed making explicit new emerging trends. Notably, we found that financial issues related to the implementation of OA are now one of the main subjects in which current efforts are focused. Also, the study of policies intended to foster the appropriation of $\mathrm{OA}$ at different levels has been the object of attention. In addition, the technological tools that allow OA to work continue to evolve. Furthermore, the changing role of institutions during the implementation of some policies has also been studied, as well as the changes OA has brought to Education. Finally, the impact OA has had on scientific research has also been studied. 
Likewise, some previous works have identified research trends in OA. Table 1 presents the main trends identified by [911], where some have similarities with the trends identified in this work. Notably, the Finances trend, presents some similarity with what has previously been identified as Business models around $\mathrm{OA}$, although this trend includes many more aspects such as the costs of OA for universities [22, 28, 30, 42, 54, 67], and transformative agreements [43].

Another trend that emerged from this work was the one related to Repositories, which in [10] in included in the OA publication channels, together with OA Journals and OA Books, and in [11] appeared in a Sub-category called "Manifestations of OA", together with OA journals and "Awareness of Open Access Manifestations". However, in this work, the studies around Repositories appear to be the focus of great interest among researchers.

The Education trend encompasses studies on the perception $[47,68]$ and use of OA to support teaching processes in higher education $[49,55,69]$. Although previous works mention the participation of Higher Education in OA dynamics [9], they focus on mandates rather than on the teaching processes.

The Perceptions trend was also found as having several works focusing on attitudes towards OA [32, 39, 48, 59], as well as on the use of resources and services available [48,57] by the academic community. Previous studies had identified the Acceptance of OA as well as the Arguments promoting OA [9].

The Tools trend includes works related to the tools aimed at facilitating the development, use, or access to digital resources are included, by integrating different resources [38, 40, 50], complementing the integration efforts [58], presenting the elements necessary for developing and publishing open academic courses, and allowing different national standards to be compatible [66]. Previous works don't seem to address the tools as such but in the relation to the actors that use some OA resources [11] or see them as a part of the technical barriers [11]. On the other hand, we identify in the results associated advances the tools used in repositories of Latin American libraries in developed countries (Argentina, Brazil, Costa Rica, Ecuador, Peru, and Mexico). These advances are associated with the roles, barriers, and benefits presented for developing and transitional countries category [11].

Next, the Policies trend is the one that coincides with previous works that have identified Policies and Mandates $[9,10]$ as an important research trend.

In terms of institutions and stakeholders, we observed that previous studies have identified actors and their roles $[9,11]$, where Authors and Librarians are included. In addition, in Scholarly Communication, identified by [11] the Commercial publishers are included. Also, the Libraries Sub-category [11] includes the role that Libraries may have as Publishers when they "offer Open Access publishing in Open Access Journals and act as mediators in the depositing of content in Institutional Repositories through Authors Self-archivation" (p. 83). This last aspect shows the changing roles we have identified as being at the essence of the Institutions and Stakeholders trends.
The last trend we identified is the one related to the impact OA has had on research [42] and knowledge management activities [60]. There is a similarity with a previous work [11] that includes Manifestations, Barriers and Benefits of $\mathrm{OA}$ as a trend, and mentions "Availability, Usability, and Visibility" of disseminated content (p. 45), which could be seen as an advantage for researchers as it positively impacts the knowledge management cycle. The two impact studies we identified state that OA has accelerated the creation, storing, retrieving, and dissemination processes creating a virtuous circle in benefit of scholarly communication [38]. However, not much work was identified in this trend, which focuses on changes in processes linked to OA scholarly communication, and not to changes in impact factors, where there are many works that have been done $[71,72]$.

\section{Conclusions}

The OA is a movement that has grown in recent years. This study focused on the analysis of the research developed on OA in HEIs to identify main research trends. The analysis initial phase was based on the SCOPUS database consultation. The result of this consultation, allowed the identification of nine trends: repositories, financial aspects, education, and perception of the academic community on the use of OA resources, supporting tools, policies on OA, stakeholders, institutions, and impact of publications on OA.

Through this study it is also determined that in addition to technology, the human and financial resources are paramount in the implementation of OA platforms. In this area, it is essential to recognize the central role that HEIs play in the implementation of the OA. Not only because of the institutional efforts concerning platforms, repositories, journals, and the articulation of their internal actors (mainly libraries, academics, and students) but, because of their negotiating power with publishers and their role as public policy actors in the matter. In any case, this work identifies the concern of HEIs about investment in the Gold route and the APC financing model for the dissemination of knowledge.

As we have shown, some works show the academic community and the public sector's acceptance of the orientations that emerged from civil society with the pillar initiatives of the OA, called BBB (Budapest. 2002; Bethesda. 2003; Berlin. 2003). These were nurtured in subsequent years with guidelines that have come from different latitudes, promoting scenarios for their enhanced development, and have therefore, contributed to an important globalization effect in the design of national OA policies and the homologation of standards by educational institutions. In turn, this provides benefits in terms of clarity around the expected contributions of the State and University actors. For example, the State is in charge of approving regulations and financing national OA repositories; while the University is in charge of the construction of institutional repositories thanks to the work of the libraries. In both cases, making strategic contributions to strengthening the OA culture in academic communities.

In the trend of education, we observe that $\mathrm{OA}$ is perceived as a resource to support the teaching process. Furthermore, the contents in OA are used both in classroom-based and distancelearning. 
It is then not surprising that diverse studies have been made about perceptions. These studies have mainly focus on the opinions of teachers and students, who have expressed their concerns throughout surveys in UK, Egypt, India, Brazil, and France. Universities have led these studies to determine the level of knowledge, attitudes, and perceptions of the academic community towards the services provided by the OA resources, being the institutional repositories, the resources that are mainly analyzed. Although the results of these surveys showed a generalized acceptance of the OA publishing model and its advantages, they also show that there are different ways of perceiving OA, and that some of these perceptions could constitute barriers to its development [9-12] given the operational, technological, political, or legal challenges involved. There is evidence that highlights the academic community's general lack of information and understanding surrounding the appropriate use of publishing licenses and OA repositories, even if it has also been determined that there exists a part of the community that does know and make use of the repositories. In [46], the authors it was noted that there are challenges to improve the visibility of the content that these resources manage, and that it is necessary to improve practices in the use of schemas of indexing descriptors (metadata). Moreover, although progress has indeed been made in the development and use of platforms and software for the management of digital collections, more efforts are necessary on the development and use of interoperability standards that facilitate the integration of $\mathrm{OA}$ with existing resources. This will improve visibility and access to content.

In terms of policy development on the OA, efforts led by civil society and the academic community has gotten back some lost domain over their research results. However, it remains a challenge to maintain and fund projects where freedom is not only for society but also for the academic community, releasing it from the responsibility of the APC. Public policies on APC should facilitate the allocation of public resources to finance them. Similarly, it is important to create fiscal policies and incentives to support the private sector.

It is also important to point out that a reorganization of two great forces is taking place: on the one hand, are those publishing companies that have generated an industry from the provision of access services to academic information and therefore, seek to maintain their profitability. On the other hand, HEIs are concerned with a process of advocating and providing information on OA. It is also evident that many of the new forms of OA reported in the reviewed literature, are proposed by the commercial publishers as a response to this global movement, to stay alive in the market in which they are intermediaries. This opens new scenarios on how to connect their research results with society, which shows the rethinking of relationships and discussions about how that knowledge is disseminated and used.

Finally, it has been established the OA has encouraged all steps in the knowledge process, changing the structure of publication and improving the dissemination mechanisms, which are all accelerators of the knowledge spiral and is potentiating scholarly communications.

\section{Conflict of Interest}

The authors declare no conflict of interest.

\section{Acknowledgment}

The Ministry of Science Technology and Innovation Colombia (MinCiencias), the Universidad Pontificia Bolivariana [587C05/2023]; the Universidad El Bosque, Universidad Autónoma de México, and the Universidad Cooperativa de Colombia [INV2564] supported this research.

The authors also want to acknowledge the valuable comments made by the reviewers; whose input greatly contributed to the strengthening of this work.

\section{References}

[1] M.A. Osorio-Sanabria, P.L. Barreto, T. Alcantara-Concepcion, A. Jaime, "Open access research trends in the education sector: A literature review," in Iberian Conference on Information Systems and Technologies, CISTI, IEEE Computer Society, 2020, doi:10.23919/CISTI49556.2020.9140935.

[2] M.R. Ghane, M.R. Niazmand, A. Sabet Sarvestani, "The citation advantage for open access science journals with and without article processing charges," Journal of Information Science, 2019, doi:10.1177/0165551519837183.

[3] Redalyc, "Declaración de México a favor del ecosistema latinoamericano de acceso abierto no comercial," Andes, 29(1), 2018.

[4] Leslie Chan, Sato Sho, Itsumura Hiroshi, Budapest Open Access Initiative (BOAI), Interlending \& Document Supply, 30(2), 89-96, 2002, doi:10.1108/ilds.2002.12230bab.012.

[5] Bethesda Statement BS, "Bethesda Statement on Open Access Publishing," 2003.

[6] S.M. Planck, Berlin Declaration on Open Access to Knowledge in the Sciences and Humanities, Revista Negotium, 0(10), 89-91, 2008.

[7] OEI, Declaración de Santo Domingo: La ciencia para el siglo XXI: una nueva visión y un marco de acción. Sala de lectura CTS+I, 1999.

[8] ICML, Declaración de Salvador sobre "Acceso Abierto": la perspectiva del mundo en desarrollo, Salvador, Bahía, Brasil, 2005.

[9] M. Collins, “Open Access Literature Review 2008-9," Library Resources \& Technical Services, 55(3), 138-147, 2011.

[10] G.F. Frosio, "Open Access Publishing: A Literature Review," SSRN Electronic Journal, 2015, doi:10.2139/ssrn.2697412.

[11] K.-I. Andersson, Developing a theory of open access: a grounded theory based literature review, Master's Thesis in Library and Information Science, Swedish School of Library and Information Science, 2016.

[12] OECD, Making Open Science a Reality OECD, 25, Paris, 2015, doi:10.1787/5jrs2f963zs1-en.

[13] P. Suber, Open Access, MIT Press, 2012.

[14] FOSTER, Open Access Definition |FOSTER, Feb. 2019.

[15] K. Petersen, S. Vakkalanka, L. Kuzniarz, "Guidelines for conducting systematic mapping studies in software engineering: An update," in Information and Software Technology, Elsevier: 1-18, 2015, doi:10.1016/j.infsof.2015.03.007.

[16] B. Kitchenham, S. Charters, D. Budgen, P. Brereton, M. Turner, S. Linkman, M. Jørgensen, E. Mendes, G. Visaggio, Guidelines for performing Systematic Literature Reviews in Software Engineering, Durham, 2007.

[17] PRISMA, PRISMA Statement, 2009.

[18] M.M. Mashroofa, W. Seneviratne B A Senior, A. Librarian, Open access initiatives and institutional repositories: Sri Lankan scenario, 2016.

[19] B. Kromp, M. Seissl, T. Zarka, "Austrian Transition to Open Access (AT2OA) - ein Überblick," Mitteilungen Der Vereinigung Österreichischer Bibliothekarinnen Und Bibliothekare, 72(1), 28-34, 2019. doi:10.31263/voebm.v72i1.2274.

[20] M. Blanca, E. Liberta Bonilla, Impacto, impacto social y evaluación del impacto, 2007

[21] M. Hall, "Green or gold? Open access after Finch," Insights: The UKSG Journal, 25(3), 235-240, 2012, doi:10.1629/2048-7754.25.3.235.

[22] S. Pinfield, C. Middleton, "Open access central funds in UK universities," Learned Publishing, 25(2), 107-114, 2012, doi:10.1087/20120205.

[23] M. Taylor, "Mapping the Publishing Challenges for an Open Access University Press," Publications, 7(4), 63, 2019 doi:10.3390/publications 7040063 .

[24] E. Gadd, D. Troll Covey, "What does 'green' open access mean? Tracking twelve years of changes to journal publisher self-archiving policies," Journal of Librarianship and Information Science, 51(1), 106-122, 2019, 
doi:10.1177/0961000616657406.

[25] R. Wellen, "Open access, Megajournals, And moocs: On the political economy of academic unbundling," SAGE Open, 3(4), 2013, doi:10.1177/2158244013507271.

[26] M. Jubb, “The 'Finch Report' and the transition to Open Access: Long term monitoring of progress in the United Kingdom," Information Services and Use, 34(3-4), 189-193, 2014, doi:10.3233/ISU-140732.

[27] N. Pontika, D. Rozenberga, "Developing strategies to ensure compliance with funders' open access policies," Insights: The UKSG Journal, 28(1), 3236, 2015, doi:10.1629/uksg.168.

[28] R. Johnson, S. Pinfield, M. Fosci, "Business process costs of implementing 'gold' and 'green' open access in institutional and national contexts," Journal of the Association for Information Science and Technology, 67(9), 22832295, 2016, doi:10.1002/asi.23545.

[29] V. McCutcheon, M. Eadie, "Managing open access with EPrints software: a case study," Insights, 29(1), 1-8, 2016, doi:10.1629/uksg.277.

[30] S. Pinfield, J. Salter, P.A. Bath, "A 'Gold-Centric' Implementation of Open Access: Hybrid Journals, the 'Total Cost of Publication,' and Policy Development in the UK and Beyond," Journal of the Association for Information Science and Technology, 68(9), 2248-2263, 2017, doi:10.1002/asi.

[31] J. Baldwin, S. Pinfield, "The UK Scholarly Communication Licence: Attempting to Cut through the Gordian Knot of the Complexities of Funder Mandates, Publisher Embargoes and Researcher Caution in Achieving Open Access," Publications, 6(3), 1-28, 2018.

[32] G.J. Johnson, "Cultural, ideological and practical barriers to open access adoption within the UK Academy: an ethnographically framed examination," Insights the UKSG Journal, 31(0), 2018, doi:10.1629/uksg.400.

[33] B. Bauer, "Austrian Transition to Open Access" 2017-2020," VOEBMitteilungen, 1-6, 2019.

[34] V.C. Capellaro, C. Kaier, "Funding conditions for open access publication funds: Open access - 'All or nothing'?," VOEB-Mitteilungen, 72(1), 74-88, 2019, doi:10.31263/voebm.v72i1.2278.

[35] V.G. Fessler, "Expansion of open access at Austrian universities: Financial needs for the years 2019-2021. Summary of the final report of the HRSM AT2OA Transition-study," VOEB-Mitteilungen, 72(1), 35-49, 2019, doi:10.31263/voebm.v72i1.2275.

[36] V.B. Kromp, F. Koren-Wilhelmer, "Funding open access transition models: Guideline for publishing agreements for the open access transformation," VOEB-Mitteilungen, 72(1), 66-73, 2019, doi:10.31263/voebm.v72i1.2277.

[37] P. Singh, "Open access repositories in India: Characteristics and future potential," IFLA Journal, 42(1), 16-24, 2016, doi:10.1177/0340035215610131.

[38] B.K. Roy, S.C. Biswas, P. Mukhopadhyay, "BURA: An open access multilingual information retrieval and representation system for Indian higher education and research institutions," Library Philosophy and Practice, 2017(1), 2017.

[39] G. Ramadoss, D. S, “Open Access Publishing Model: Preferences, Opportunities, and Challenges - An Opinion Survey Among Teaching Staff in Higher Education Institutions in Tamilnadu," Library Philosophy and Practice (e-Journal), 2613, 2019.

[40] S.C. Swain, "Formation and Open Access of Institutional Electronic Research Corners for Promotion of Communication Facilities and Quality Research," International Journal of Emerging Technologies in Learning (IJET), 15(06), 192-199, 2020, doi:10.3991/ijet.v15i06.12003.

[41] B. Sekabembe, J. Ssempebwa, Bridging the Knowledge Gap for African Researchers through Open Access Publishing: The Case of African Higher Education Research Online (AHERO), 95-103, 2011, doi:10.1007/978-3642-19715-4_10.

[42] L. Czerniewicz, S. Goodier, "Open access in South Africa: A case study and reflections," South African Journal of Science, 110(9-10), 2014, doi:10.1590/sajs.2014/20140111.

[43] A.C. Bawa, "South Africa's journey towards open access publishing," Biochemist, 42(3), 30-33, 2020, doi:10.1042/BIO20200029.

[44] R.T. Enakrire, J.M. Ngoaketsi, "Open access practices: roadmap to research paper publications in academic institutions," Library Hi Tech News, 37(5), 13-15, 2020, doi:10.1108/LHTN-01-2020-0003.

[45] V. Picasso, L. Phelan, "La evolución del acceso abierto a la investigación y a los datos en la educación superior en Australia," RUSC Universities and Knowledge Society Journal, 11(3), 128-141, 2014, doi:10.7238/rusc.v11i3.2076.

[46] K. McNaught, "The changing publication practices in academia: Inherent uses and issues in open access and online publishing and the rise of fraudulent publications," Journal of Electronic Publishing, 18(3), 1-1, 2015, doi:10.3998/3336451.0018.308.

[47] M. Shah, M. Cheng, "Exploring factors impacting student engagement in open access courses," Open Learning, 34(2), 187-202, 2019, doi:10.1080/02680513.2018.1508337.

[48] A.C.M. Furnival, N.S. Silva-Jerez, "Percepções de pesquisadores brasileiros sobre o acesso aberto à literatura científica,” Informacao e Sociedade, 27(2), 153-166, 2017, doi:10.22478/ufpb.1809-4783.2017v27n2.32667.

[49] E.M. de Oliveira Costa, J. Santa Anna, "Acesso aberto e educação a distância : novas configurações para a democratização do conhecimento," 3, 536-546, 2019.

[50] D.S. Moreira, L.A.S. da Silva, A.E. Yanai, "Interoperabilidade de sistemas para viabilização do acesso aberto aos relatórios de iniciação científica da UFAM," Ciência Da Informação, 48(3 (Supl.)), 490-491, 2019.

[51] S.I. Adame, L. Lloréns Baez, M. Schorr Wiener, "Retrospectiva de los repositorios de acceso abierto y tendencias en la socialización del conocimiento educativa: REDIE.," Revista Electrónica de Investigación Educativa, 15(2), 148-162, 2013.

[52] G.C.T. Sepúlveda, M.M. Reyes, A.S. Martín, “Open access repositories in higher education institutions in Mexico, An initial review using the SCOT methodology," Informacion, Cultura y Sociedad, 40(junio), 117-130, 2019, doi:10.34096/ics.i40.5317.

[53] P. Renfro, "Open access within reach: An agenda for action," Journal of Library Administration, 51(5-6), 464-475, 2011, doi:10.1080/01930826.2011.589351.

[54] K. Okamoto, "Making Higher Education More Affordable, One Course Reading at a Time: Academic Libraries as Key Advocates for Open Access Textbooks and Educational Resources," Public Services Quarterly, 9(4), 267-283, 2013, doi:10.1080/15228959.2013.842397.

[55] J.A. Corrigan, N. Ng-A-Fook, "Mobilizing curriculum studies in a (Virtual) world: Open access, edupunks, and the public good," Canadian Journal of Education, 35(2), 58-76, 2012.

[56] E.M. Bodero, M. De Giusti, C.D. Radicelle, E.P. Villacrés, “Análisis de los repositorios digitales institucionales de Acceso Abierto en el Ecuador Analyses of institutional Open Access digital repositories in Ecuador Contenido," Revista Espacios, 40, 1-9, 2019.

[57] M. Mourad, "Students' adoption of an open access online education service An exploratory study in an emerging higher education (HE) market," Online Information $\quad$ Review, $\quad 34(4), \quad 604-617, \quad 2010$, doi:10.1108/14684521011073007.

[58] M. Ojsteršek, J. Brezovnik, M. Kotar, M. Ferme, G. Hrovat, A. Bregant, M. Borovič, "Establishing of a Slovenian open access infrastructure: A technical point of view," Program, 48(4), 394-412, 2014, doi:10.1108/PROG-022014-0005.

[59] C. Okret-Manville, "Academic Social Networks and Open Access: French Researchers at the crossroads," LIBER QUARTERLY, 25(3), 118-135, 2016, doi:10.18352/lq.10131.

[60] S. Bernius, "The impact of open access on the management of scientific knowledge," Online Information Review, 34(4), 583-603, 2010, doi:10.1108/14684521011072990.

[61] F.C. Ratanya, "Electronic theses and dissertations (ETD) as unique open access materials: Case of the Kenya Information Preservation Society (KIPS)," Library Hi Tech News, 27(4), 15-20, 2010, doi:10.1108/07419051011083190.

[62] K.N. Igwe, "Open access repositories in academic and research institutions for the realization of Nigeria's Vision 20: 2020," International Journal of Information Science and Management, 12(1), 33-46, 2014.

[63] M. Boufarss, M. Laakso, "Open Sesame? Open access priorities, incentives, and policies among higher education institutions in the United Arab Emirates," Scientometrics, 124(2), 1553-1577, 2020, doi:10.1007/s11192020-03529-y.

[64] C.T. Chisita, B. Chiparausha, “Open Access initiatives in Zimbabwe: Case of academic libraries," The Journal of Academic Librarianship, 45(5), 1-8, 2019, doi:10.1016/j.acalib.2019.102047.

[65] E. Tzoc, "El Acceso Abierto en América Latina: Situación actual y expectativas," Rev. Interam. Bibliot. Medellín (Colombia), 35(1), 83-95, 2012.

[66] D.G. Sampson, P. Zervas, "Supporting open access to European academic courses: The ASK-CDM-ECTS tool," Campus-Wide Information Systems, 30(1), 44-62, 2012, doi:10.1108/10650741311288814.

[67] G. Machovec, "The Impact of Gold Open Access Journals in Aggregators and Abstracting/Indexing Services," Journal of Library Administration, 56(7), 875-883, 2016, doi:10.1080/01930826.2016.1216227.

[68] A.M. Salaz, N. Johnston, C. Pickles, "Faculty Members Who Teach Online: A Phenomenographic Typology of Open Access Experiences," Journal of Academic Librarianship, 44(1), 125-132, 2018, 
doi:10.1016/j.acalib.2017.09.006.

[69] E. Gadd, C. Morrison, J. Secker, "The impact of open access on teachinghow far have we come?," Publications, 7(3), 2019, doi:10.3390/publications7030056.

[70] V. Martinovich, "Argentine open access scientific journals with international circulation: An analysis from Pierre Bourdieu's field theory," Informacion, Cultura y Sociedad, 40(junio), 93-116, 2019, doi:10.34096/ics.i40.5540.
[71] S. Gunasekaran, S. Arunachalam, "The impact factors of open access and subscription journals across fields," Current Science, 107(3), 380-388, 2014, doi:10.18520/cs/v107/i3/380-388.

[72] I.K. Razumova, A. Kuznetsov, "Impact of open access models on citation metrics," Journal of Information Science Theory and Practice, 7(2), 23-31, 2019, doi:10.1633/JISTaP.2019.7.2.2. 